\title{
Effects of in vitro fermentation of barley beta-glucan and sugar beet pectin using human fecal inocula on cytokine expression by dendritic cells
}

Citation for published version (APA):

Rosch, C., Taverne, N., Venema, K., Gruppen, H., Wells, J. M., \& Schols, H. A. (2017). Effects of in vitro fermentation of barley beta-glucan and sugar beet pectin using human fecal inocula on cytokine expression by dendritic cells. Molecular Nutrition \& Food Research, 61(1), [1600243]. https://doi.org/10.1002/mnfr.201600243

Document status and date:

Published: 01/01/2017

DOI:

10.1002/mnfr.201600243

Document Version:

Publisher's PDF, also known as Version of record

Document license:

Taverne

Please check the document version of this publication:

- A submitted manuscript is the version of the article upon submission and before peer-review. There can be important differences between the submitted version and the official published version of record.

People interested in the research are advised to contact the author for the final version of the publication, or visit the DOI to the publisher's website.

- The final author version and the galley proof are versions of the publication after peer review.

- The final published version features the final layout of the paper including the volume, issue and page numbers.

Link to publication

\footnotetext{
General rights rights.

- You may freely distribute the URL identifying the publication in the public portal. please follow below link for the End User Agreement:

www.umlib.nl/taverne-license

Take down policy

If you believe that this document breaches copyright please contact us at:

repository@maastrichtuniversity.nl

providing details and we will investigate your claim.
}

Copyright and moral rights for the publications made accessible in the public portal are retained by the authors and/or other copyright owners and it is a condition of accessing publications that users recognise and abide by the legal requirements associated with these

- Users may download and print one copy of any publication from the public portal for the purpose of private study or research.

- You may not further distribute the material or use it for any profit-making activity or commercial gain

If the publication is distributed under the terms of Article $25 \mathrm{fa}$ of the Dutch Copyright Act, indicated by the "Taverne" license above, 


\title{
Effects of in vitro fermentation of barley $\beta$-glucan and sugar beet pectin using human fecal inocula on cytokine expression by dendritic cells
}

\author{
Christiane Rösch ${ }^{1,3}$, Nico Taverne ${ }^{2}$, Koen Venema ${ }^{3,4}$, Harry Gruppen ${ }^{1}$, Jerry M. Wells ${ }^{2}$ \\ and Henk A. Schols ${ }^{1,3}$ \\ ${ }^{1}$ Laboratory of Food Chemistry, Wageningen University, Wageningen, the Netherlands \\ ${ }^{2}$ Host Microbe Interactomics, Wageningen University, Wageningen, the Netherlands \\ ${ }^{3}$ Top Institute Food and Nutrition, Wageningen, the Netherlands \\ ${ }^{4}$ Beneficial Microbes Consultancy, Wageningen, the Netherlands
}

Scope: This study simulates the fermentation process of barley $\beta$-glucan and sugar beet pectin in the human colon and monitors the degradation products formed. Additionally, immune effects of the degradation products were investigated.

Methods and results: Immunostimulatory activity of fermentation digesta was investigated using bone marrow derived dendritic cells (BMDCs) from toll-like receptor 2/4 (TLR2/4) knockout mice, which were unresponsive to microbe-associated molecular patterns. Cytokine responses were elicited to dietary fibers and not to the SCFA and microbiota. The fermentation digesta were analyzed for their SCFA profiles and glycan metabolites over time. During fermentation the amount of insoluble precipitating fibers increased and induced as well as soluble molecules of lower molecular mass greater amounts of cytokines in BMDCs than the parental fiber. Additionally, high amounts of cytokines can be attributed to soluble galactose-rich beet pectin molecules.

Conclusions: The fermentation of the two fibers led to fiber-specific amounts of SCFA, glycosidic metabolites, and different immunomodulatory properties. BMDC from TLR2/4 knockout mice did not respond to the digest microbiota and SCFA, making it a useful approach to study temporal effects of fermentation on the immunomodulatory effects of fibers.

\section{Keywords:}

Batch fermentation / Dendritic cells / Digesta / Human fecal inocula / Immunomodulation

Additional supporting information may be found in the online version of this article at the publisher's web-site
Received: March 17, 2016

Revised: June 14, 2016

Accepted: June 19, 2016
Correspondence: Prof. Henk A. Schols

E-mail: henk.schols@wur.nl

\begin{abstract}
Abbreviations: BMDC, bone marrow derived DC; DC, dendritic cell; DP, degree of polymerization; HPAEC, high performance anion exchange chromatography; HMI, host microbiota interaction; HPSEC, high performance size exclusion chromatography; IMW, intermediate molecular weight; KO, knock out; LMW, low molecular weight; OS, oligosaccharide; PS, polysaccharide; RG, rhamnogalacturonan; RT, room temperature; SBP, sugar beet pectin; SHIME, simulator of the human intestinal microbial ecosystem; TLR, toll-like receptor; TNF, tumor necrosis factor
\end{abstract}

\section{Introduction}

Barley $\beta(1,3)(1,4)$ glucan and sugar beet pectin (SBP) are dietary fibers. Thus, they are indigestible in the human small intestine and end up in the large intestine, where they are fermented by the microbiota [1]. Many fermentation studies of dietary fibers have investigated their influence on microbiota composition, possible prebiotic effects and production of SCFA $[2,3]$. The microbiota and SCFA are known to influence epithelial functions and immune regulation in the large bowel $[4,5]$. Cryptopatches and isolated lymphoid follicles in the colon have been reported to contain M cells, which may transport particulate antigens from the lumen to dendritic cells (DCs), macrophages, and lymphocytes in the lymphoid follicles underlying the follicular epithelium [6]. 
Dietary $\beta(1,3)$-linked glucans found in cell walls of mushrooms and other fungi can elicit immune responses though binding of the $\beta(1,3)$-linked glucans to dectin-1, a member of the C-type lectin receptor family $[7,8]$. Expression of the C-type lectin receptor dectin-1 was recently detected in human colonic intestinal epithelial cells [9] and was shown to be expressed in primary colonic enterocytes and induce chemokine secretion upon ligand binding to $\beta(1,3)$-linked glucans [10].

Barley-derived $\beta$-glucan is a linear polysaccharide (PS) consisting of $\beta(1,3)$ - and $(1,4)$-linked glucose units. SBP is a much more complex fiber consisting of a homogalacturonan region that is highly methylesterified and acetylated. In addition, SBP consists of a rhamnogalacturonan region I (RG I), which is composed of alternating rhamnose and galacturonic acid units and is substituted with short neutral side chains of galactose and arabinose $[11,12]$.

Several in vitro fermentation models have been used for studies on microbiota and substrates, which all have the general limitation that they are not equipped with a mucus layer, epithelial, and other intestinal cells to take up metabolites or study effects on the host [13]. A recent development to overcome this limitation is the host microbiota interaction (HMI) model that can be connected to the simulator of the human intestinal microbial ecosystem (SHIME) fermentation model. The HMI model has a mucus layer and semipermeable layer (double functional layer), which protect the epithelial cells from the bacteria while allowing transport of low molecular weight (LMW) metabolites and oxygen diffusion [14]. When filtered yeast digesta from the SHIME fermentation model were incubated in coculture with epithelial and THP1 immune cells, proinflammatory cytokine secretion was decreased [15]. Currently, this is the only study measuring the effect of filtered fermentation digesta on cytokine responses in immune cells. However, one limitation of the HMI/SHIME model is that insoluble fiber particles that are known to be immunomodulatory [16] are excluded due to filtration.

In our in vitro batch fermentation, we monitor the degradation products formed during barley $\beta$-glucan and SBP fermentation using human fecal microbiota and investigate the immunomodulatory activity of complete digesta using bone marrow derived DCs (BMDCs) from toll-like receptor 2/4 (TLR2/4) knockout (KO) mice.

\section{Materials and methods}

\subsection{Substrates}

Barley $\beta$-glucan of low viscosity (Megazyme, Bray, Ireland) and a previously characterized SBP (DuPont, Brabrand, Denmark) [11], were used for the fermentation studies.

LPS from Escherichia coli (Sigma-Aldrich, St Louis, MO, USA) was used as a control to show unresponsiveness of the BMDCs from TLR2/4 KO mice to this common microbe- associated molecular pattern. Depleted zymosan, an insoluble $\beta 1$,3-glucan from Saccharomyces cerevisiae (Invivogen, Toulouse, France) was used as a positive control in the immunoassays.

\subsection{Culture medium for in vitro fermentation}

The culture medium was based on the standard ileal efflux medium and modified as described elsewhere [17]. All medium components were obtained from Tritium Microbiology (Veldhoven, The Netherlands). The medium included a 1 M MES (2-( $N$-morpholino)ethanesulfonic acid hydrate) buffer to maintain $\mathrm{pH} 5.8$, mimicking the $\mathrm{pH}$ conditions in the proximal colon [17].

\subsection{Human fecal inoculum}

Standardized, pooled fecal inoculum from eight healthy European adults (25-45 years old) was obtained from TNO (Zeist, the Netherlands), prepared and validated as described elsewhere [18]. The subjects were not treated with antibiotics 2 months before fecal donation. The fecal inoculum was activated in standard ileal efflux medium culture medium for 16 $\mathrm{h}$ and ten times with medium before use.

\subsection{In vitro fermentation}

For each time point, two $20 \mathrm{~mL}$ fermentation bottles were filled with $9 \mathrm{~mL}$ culture medium, $100 \mathrm{mg}$ barley $\beta$-glucan, and $1 \mathrm{~mL}$ of the activated diluted fecal inoculum. SBP was presolubilized in medium solution and equally portioned in the appropriate fermentation bottle and inoculated with $1 \mathrm{~mL}$ of activated diluted inoculum. Hence, at the start of both fermentation experiments the fecal inoculum was diluted 100 times and fiber concentrations were $10 \mathrm{mg} / \mathrm{mL}$. The bottles were immediately closed with rubber stoppers in an anaerobic chamber, sealed with an aluminum cap and incubated at $37^{\circ} \mathrm{C}$ with shaking at $130 \mathrm{rpm}$ for a maximum of $48 \mathrm{~h}$. Blanks with either no substrate or no inoculum were prepared as controls. Samples were taken for analysis after 0 , $5,11,24$, and $48 \mathrm{~h}$ for barley $\beta$-glucan and $0,6,11,12,24$, and $48 \mathrm{~h}$ for SBP. At each time point $5.5 \mathrm{~mL}$ of the fermentation mixture was heated for $5 \mathrm{~min}$ at $100^{\circ} \mathrm{C}$ to stop bacterial activity.

\subsection{Chemical analyses}

\subsubsection{Constituent monosaccharide composition}

SBP fermentation digesta were separated into soluble and insoluble fractions by centrifugation (10 $\mathrm{min}$, RT (room temperature), $18000 \times$ g). The constituent monosaccharide 
composition of the dried soluble and insoluble SBP fermentation fractions was determined in duplicate using a prehydrolysis step with $72 \% \mathrm{w} / \mathrm{w}$ sulfuric acid at $30^{\circ} \mathrm{C}$ for $1 \mathrm{~h}$, followed by hydrolysis with $1 \mathrm{M}$ sulfuric acid at $100^{\circ} \mathrm{C}$ for 3 $\mathrm{h}$. The monosaccharides released, were derivatized to alditol acetates and analyzed by GC using inositol as an internal standard [19]. The presence of uronic acid in the samples was quantified by using the colorimetric m-hydroxydiphenyl assay [20] automated on a Skalar Autoanalyzer (Skalar, Breda, the Netherlands) [21].

\subsubsection{Molecular weight distribution using HPSEC}

The fermentation samples were centrifuged (10 $\mathrm{min}$, RT, $18000 \times \mathrm{g}$ ) and the supernatant was analyzed for molecular weight distribution of soluble PS present, by high performance size exclusion chromatography (HPSEC) on an U1timate 3000 HPLC (Dionex, Sunnyvale, CA, USA) equipped with a Shodex RI-101 refractive index detector (Showa Denko, Tokyo, Japan). Three TSK-Gel columns connected in series (4000-3000-2500 SuperAW; $150 \times 6 \mathrm{~mm}$ ) were used for the analysis. These columns were preceded by a TSK Super AW-L guard column $(35 \times 4.6 \mathrm{~mm}$; Tosoh Bioscience, Tokyo, Japan) and covered a molecular mass range from 0 to $250 \mathrm{kDa}$. Twenty microliters samples were injected and eluted with $0.2 \mathrm{M} \mathrm{NaNO}_{3}$, at $40^{\circ} \mathrm{C}$ with a flow rate of $0.6 \mathrm{~mL} / \mathrm{min}$. Pullulan molecular mass standards (Polymer Laboratories, Palo Alto, CA, USA) were used for calibration.

\subsubsection{Oligosaccharide profiling with HPAEC}

After centrifugation of the fermentation samples (10 min, RT, $18000 \times g)$ the supernatants were analyzed for their oligosaccharide (OS) profile using high performance anion exchange chromatography (HPAEC) on an ICS5000 system (Dionex), with a CarboPac PA-1 column $(2 \times 250 \mathrm{~mm})$ in combination with a Carbopac PA-1 guard column $(2 \times 50 \mathrm{~mm})$. The elution conditions for barley $\beta$-glucan digesta were the following: the flow rate was $0.3 \mathrm{~mL} / \mathrm{min}$ with an eluent profile starting with $0.02 \mathrm{M} \mathrm{NaOH}$ until $13 \mathrm{~min}$, then increasing to $0.1 \mathrm{M} \mathrm{NaOH}$ in $15 \mathrm{~min}$. The OSs were eluted from the column using a gradient of $0-500 \mathrm{mM} \mathrm{NaOAc}$ in $1 \mathrm{M} \mathrm{NaOH}$ (B) from 15 to $45 \mathrm{~min}$, followed by a gradient to $100 \% \mathrm{~B}$ from 45 to 46 min, which was held for $7 \mathrm{~min}$. After this, the column was reequilibrated with $0.1 \mathrm{M} \mathrm{NaOH}$ (A) for $3 \mathrm{~min}$ and $0.02 \mathrm{M}$ $\mathrm{NaOH}$ for $20 \mathrm{~min}$. The elution gradient for SBP was different in the following condition: starting with 0-36 min from $0 \% \mathrm{~B}$ to $40 \% \mathrm{~B}, 36-40 \mathrm{~min}$ at $100 \% \mathrm{~B}$, and $40-55 \mathrm{~min}$ at $100 \% \mathrm{~A}$. An ICS5000 ED (Dionex) pulsed amperometric detector and Chromeleon software version 7 were used for detection and analysis.

\subsubsection{SCFA}

SCFAs were analyzed on a TRACE GC Ultra Gas Chromatograph system coupled with a FID detector (Interscience, Breda, the Netherlands), as described elsewhere [22]. Briefly, $50 \mu \mathrm{L}$ of samples or standards were mixed with $50 \mu \mathrm{L}$ of 0.15 $\mathrm{M}$ oxalic acid, after $30 \mathrm{~min} 150 \mu \mathrm{L}$ water was added and $1 \mu \mathrm{L}$ of the sample was analyzed.

\subsection{Generation and stimulation of BMDCs}

To obtain BMDCs, 6- to 10-week-old C57bl/6 mice lacking both TLR2 and TLR4 were euthanized and the femurs isolated, washed and gently crushed in $10 \mathrm{~mL}$ of RPMI-1640 medium (without HEPES) supplemented with 100 units $/ \mathrm{mL}$ penicillin G (Invitrogen, Breda, the Netherlands) and 100 $\mu \mathrm{g} / \mathrm{mL}$ streptomycin (Invitrogen). BM cells were filtered using a Steriflip Filter Unit (Millipore, Billerica, MA, USA) and around $2-4 \times 10^{4}$ cells per well were seeded in a 96-well flat bottom plate in complete media (RPMI-1640 medium containing $10 \%$ heat-inactivated fetal calf serum (Sigma-Aldrich), 100 units $/ \mathrm{mL}$ penicillin G, $100 \mu \mathrm{g} / \mathrm{mL}$ streptomycin, $20 \mathrm{ng} / \mathrm{mL}$ of recombinant mouse granulocytemacrophage colony-stimulating-factor (R\&D systems, Minneapolis, MN, USA) and $0.05 \mathrm{mM}$ of $\beta$-mercaptoethanol). Cells were incubated at $37^{\circ} \mathrm{C}$ in $5 \% \mathrm{v} / \mathrm{v} \mathrm{CO}_{2}$ atmosphere and the medium was changed every 3 days. On day 6, BMDCs were stimulated with $400 \mu \mathrm{g} / \mathrm{mL}$ fiber, freeze-dried digesta, or digesta blanks containing microbiota and fermentation medium. Other blanks were SCFA (acetic-, propionic-, butyric acid all in $0.1,0.5$, and $1 \mathrm{mg} / \mathrm{mL}$ concentrations in MES buffer), LPS (1 $\mu \mathrm{g} / \mathrm{mL})$, depleted zymosan $(20 \mu \mathrm{g} / \mathrm{mL})$, or medium.

\subsection{Cytokine quantification in culture supernatants}

Supernatants from the BMDC stimulation assays were collected after stimulation for $24 \mathrm{~h}$. They were analyzed for the presence of cytokines (IL-6, IL-10, monocyte chemoattractant protein (MCP) I and tumor necrosis factor (TNF)) using a cytometric bead based BD mouse inflammation kit that enables multiplex measurements to be made in the same sample (BD Biosciences, Breda, the Netherlands) [23]. The sensitivity LODs, as described by the manufacturer, were as follows: 5.0, 17.5, 52.7, and 7.3 pg/mL for IL-6, IL-10, MCP-I, and TNF, respectively. In the mouse TNF is a synonym for TNF- $\alpha$. The flow cytometry data were analyzed using the BD FCAP software (BD Biosciences).

\subsection{Statistics}

All statistical tests were performed using Prism 5.0 software (GraphPad, San Diego, CA, USA). Data shown are the 
means and the SEM. Data were tested for normality with the D'Agostino and Pearson normality test. Statistical analyses of normally distributed data were performed with the two tailed unpaired T-test. Data that did not show a normal distribution were analyzed with the Welch's correction to determine equal variances between the groups. When the variances were unequal between the groups, the data were analyzed using the unpaired T-test with Welch's correction. Differences were considered statistically significant, highly significant and extremely significant when the $p$ value were $<0.05,<0.001$, or $<0.0001$, respectively.

\section{Results and discussion}

\subsection{Physicochemical and immunological characteristics of barley $\beta$-glucan and SBP}

The monosaccharide composition showed that barley $\beta$ glucan consists of 99 mol\% glucose. SBP consists for 80 mol\% of galacturonic acid forming the pectin backbone next to small amounts of rhamnose ( $2 \mathrm{~mol} \%)$, arabinose ( $6 \mathrm{~mol} \%)$ and galactose $(12 \mathrm{~mol} \%)$. Of all galacturonic acid residues 53 mol \% are methylesterified and 17 mol\% acetylated [11]. The protein content of $\beta$-glucan and SBP was $<1$ and $4.8 \mathrm{w} / \mathrm{w} \%$, respectively. At RT $25 \mathrm{w} / \mathrm{w} \%$ of $\beta$-glucan and $37 \mathrm{w} / \mathrm{w} \%$ of SBP was water soluble (no further data shown).

In previous studies we have shown that the barley $\beta$-glucan and SBP used in this study, induced different amounts of cytokines in BMDCs from TLR2/4 KO mice, depending on fractions used and the treatments (Supporting Information Fig. 1). The parental suspensions and particulate fractions were more immunostimulatory than the soluble fractions. Heating the suspended substrates at $80^{\circ} \mathrm{C}$ for $10 \mathrm{~min}$ completely dissolved the substrates, resulting in a reduction in cytokine secretion by stimulated BMDCs. Freeze drying and resuspending the solubilized material increased the cytokine production of stimulated BMDCs (Supporting Information Fig. 1). This indicates that the immunostimulatory activity of the two pure substrates was partly affected by freeze drying and heating, which was used to stop enzymatic reactions in samples of the fermentation digesta.

\section{2 $\mathrm{pH}$ monitoring of in vitro batch fermentation of fibers}

The $\mathrm{pH}$ of the barley $\beta$-glucan in vitro batch fermentation started to increase from 5.8 to 6.2 within $8 \mathrm{~h}$ of fermentation. This may indicate the microbial utilization of protein in the medium at the beginning of the fermentation, due to a lack in degradability of the barley $\beta$-glucans, resulting in the production of ammonia instead of SCFA [24]. The $\mathrm{pH}$ then fluctuated to $5.9(10 \mathrm{~h}), 6.2(11 \mathrm{~h}), 6.3(24 \mathrm{~h})$, and 6.0 (48 h). These minimal $\mathrm{pH}$ changes over time suggest the presence of different glucan populations of different fermentability.
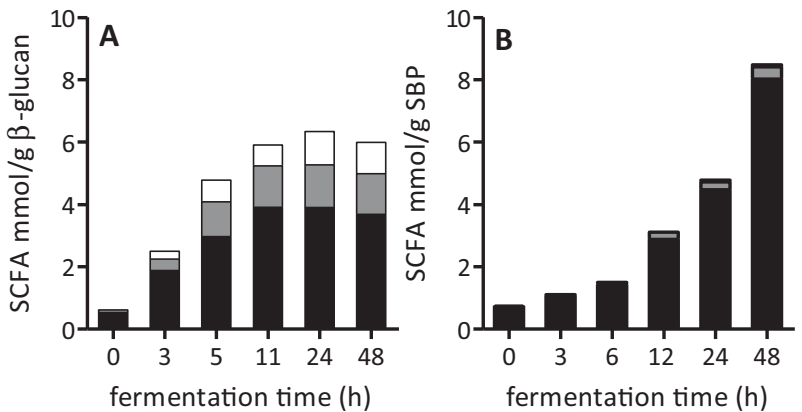

Figure 1. Levels of SCFA produced during the fermentation of barley $\beta$-glucan (A) and SBP (B) using human fecal inocula. Acetic acid (black), propionic acid (gray), and butyric acid (white).

The $\mathrm{pH}$ of the SBP fermentation increased from 5.8 to 6.0 within $9 \mathrm{~h}$ of fermentation and can be accounted for the microbial utilization of proteins in the medium as described above (Fig. 1). From 12 to $48 \mathrm{~h}$ of fermentation a decrease to a $\mathrm{pH}$ of 5.5 was observed, due to a relatively high increase in acids (SCFA and nonmethyl esterified galacturonic acid residues) (see below).

\subsubsection{SCFA production}

The microbial production of SCFAs during in vitro fermentation is one of the indicators of fermentability of the fiber and is discussed separately for each fiber.

\subsubsection{Barley $\beta$-glucan fermentation}

After $3 \mathrm{~h}$ fermentation the production of SCFA started to increase from $2.5 \mathrm{mmol} / \mathrm{g}$ barley $\beta$-glucans to a maximum of $6.3 \mathrm{mmol} / \mathrm{g}$ barley $\beta$-glucans at $24 \mathrm{~h}$, of which 1.4 and 1.1 $\mathrm{mmol} / \mathrm{g}$ barley $\beta$-glucans were propionic and butyric acid, respectively (Fig. 1A). Together they constitute ca. $30 \mathrm{mmol} \%$ of the total SCFA from $3 \mathrm{~h}$ onwards. The remaining part $(70$ $\mathrm{mmol} \%$ ) was acetic acid, reaching a maximum of $3.9 \mathrm{mmol} / \mathrm{g}$ barley $\beta$-glucans at $24 \mathrm{~h}$ and remaining constant till $48 \mathrm{~h}$. The molecular ratio of acetic, propionic and butyric acid at $48 \mathrm{~h}$ was 67:21:12.

\subsubsection{SBP fermentation}

The SCFA production of SBP seems to be in exponential increase and within $12 \mathrm{~h}$ fermentation ca. $40 \%$ of the total SCFA present at $48 \mathrm{~h}$ are produced (Fig. 1B). The fermentation of SBP led to minor amounts of propionic acid (maximum 5 mmol\% of total SCFA) and butyric acid (1 mmol\% of the total SCFA) at $48 \mathrm{~h}$. The molecular ratio of acetic, propionic, and butyric acid after $48 \mathrm{~h}$ fermentation was 95:5:1.

Overall, SBP was fermented much slower than $\beta$-glucan (Fig. 1). At $12 \mathrm{~h} \mathrm{SBP}$ fermentation only $40 \mathrm{mmol} \%$ of total SCFA was produced, while at $11 \mathrm{~h}$ of $\beta$-glucan fermentation more than $90 \mathrm{mmol} \%$ of the total SCFA present at $48 \mathrm{~h}$ was 
produced. The increase in SCFA for the SBP fermentation at $12 \mathrm{~h}$ is in line with the $\mathrm{pH}$ decrease from that time point onwards. This correlation between $\mathrm{pH}$ and SCFA produced is less pronounced due to the small $\mathrm{pH}$ fluctuations during the $\beta$-glucan fermentation. The total amounts of SCFA formed at the end of the fermentation (48 h) were larger for the SBP fermentation ( $8.5 \mathrm{mmol} / \mathrm{g} \mathrm{SBP} ; 6.3 \mathrm{mmol} / \mathrm{g} \beta$-glucan), which is reflected in the end $\mathrm{pH}$ of the $48 \mathrm{~h}$ time points and indicates that the two substrates are fermented by the human microbiota at different rates and probably also to a different extent.

\subsection{Fermentation digesta in immunoassays on BMDCs}

As we showed that the two substrates were inducing cytokine secretion in BMDCs (Supporting Information Fig. 1), it was of interest to determine whether the glycosidic fermentation metabolites were also immune stimulating. The freeze-dried digesta from selected time points were tested for their capacity to elicit cytokine production in BMDCs. As was previously demonstrated (Supporting Information Fig. 3), the BMDCs from TLR2/4 KO mice were unresponsive to common bacterial molecular structures such as LPS and LTA that were anticipated to be present in the digesta [25]. Additionally, it was shown that these BMDCs were also unresponsive to flagellin (unpublished data), a component of bacterial flagella, which is normally recognized by TLR5 [26].

The high concentrations of fecal bacterial cell wall material and the possible presence of SCFA in the digesta could influence the cytokine response in these assays. To test this possibility, fermentation microbiota controls containing only the starting microbiota and fermentation medium (but no substrate) at different fermentation time points (t $0,12,24$, $48 \mathrm{~h}$ ) (Fig. 2) as well as different concentrations of the three main SCFA were tested for their capacity to elicit cytokine secretion (Supporting Information Fig. 2). Only low amounts of cytokines (e.g. $<900 \mathrm{pg} / \mathrm{mL}$ TNF) were induced in BMDCs by the SCFA controls, which were not significant for TNF, IL-6, and IL-10 levels compared to the medium. The positive control depleted zymosan, which induces cytokines through dectin-1 signaling [27], induced still high amounts of cytokines (14192 pg/mL TNF) (Supporting Information Fig. 2). Although some fermentation microbiota blanks induced significant amounts of cytokines compared to the medium control (e.g. 3256 vs. $211 \mathrm{pg} / \mathrm{mL}$ TNF, respectively) the amounts of cytokines elicited by the digesta containing fiber were substantially greater than for the microbiota blanks (Fig. 2). It is unlikely that a change in the microbiota composition would cause such effects as the BMDCs do not respond to common microbe-associated molecular patterns found on both Grampositive and Gram-negative bacteria (Supporting Information Fig. 3).

For the digesta containing $\beta$-glucan or SBP, all four cytokines were induced in significantly increased amounts of cytokines compared to the microbiota controls (e.g. 18506 and $933 \mathrm{pg} / \mathrm{mLTNF}$ for $\beta$-glucan $11 \mathrm{~h}$ and control $0 \mathrm{~h}$, respectively) (Fig. 2). This demonstrates that the cytokines were induced by the PSs present in the fermentation digesta (Fig. 2 and Supporting Information Fig. 2). For both substrates a continuous increase of all four cytokines over fermentation time with maxima at $11 \mathrm{~h}$ for $\beta$-glucan and $24 \mathrm{~h}$ for SBP fermentation, was observed. This showed that the fermentation degradation products are more immunomodulatory than the parental fiber at $0 \mathrm{~h}$. Furthermore, the digesta were not affected by sample preparation steps such as heating or freeze drying as described above for the pure fibers. This was probably due to the high salt concentration of the fermentation digesta. This allowed us to draw conclusions about the immunomodulatory capacity of the fiber components present in the digesta at specific time points and will be discussed in more detail.

Our approach to study immunomodulatory effects of fermentation digesta with TLR2/4 KO mice is highly relevant to studies of immunomodulation by fibers because in the healthy intestine the mucus barrier spatially compartmentalizes bacteria to the luminal compartment of small and large intestine, limiting the induction of innate responses in the epithelium by microbes [28-30]. Additionally, the normal human colonic epithelial cells and lamina propria cells express low levels of TLR4 and its coreceptor MD-2 and the uninflamed epithelium is normally LPS unresponsive [31]. Fiber particles and digesta that are smaller than bacteria are likely to be able to diffuse through the mucus barrier and interact with pattern-recognition receptors such as dectin-1, which is expressed in epithelial cells [9].

\subsubsection{Immunomodulatory effects of soluble and insoluble fiber}

As it was shown that the intact fibers and their degradation products induced cytokines in BMDCs, the fiber products present at each time point were of interest. Previous studies on these two intact fibers showed a positive correlation between dose and amounts of induced cytokines (unpublished data). The insoluble $\beta$-glucans and SBP induced much higher amounts of cytokines than the soluble $\beta$-glucans and SBP fractions (Supporting Information Fig. 1). Hence, the amounts of soluble and insoluble dietary fiber in the digesta in relation to immunomodulation are of interest.

Due to very small sample amounts and the viscous characteristic of the $\beta$-glucan digesta, it was difficult to precisely separate the soluble and insoluble components of the $\beta$-glucan digesta, resulting in unreliable quantification of the soluble and insoluble $\beta$-glucans, using the enzyme kit (AACC Method 32-23.01, Megazyme). Hence, the immunomodulatory effects of soluble and insoluble $\beta$-glucans are not discussed further. 

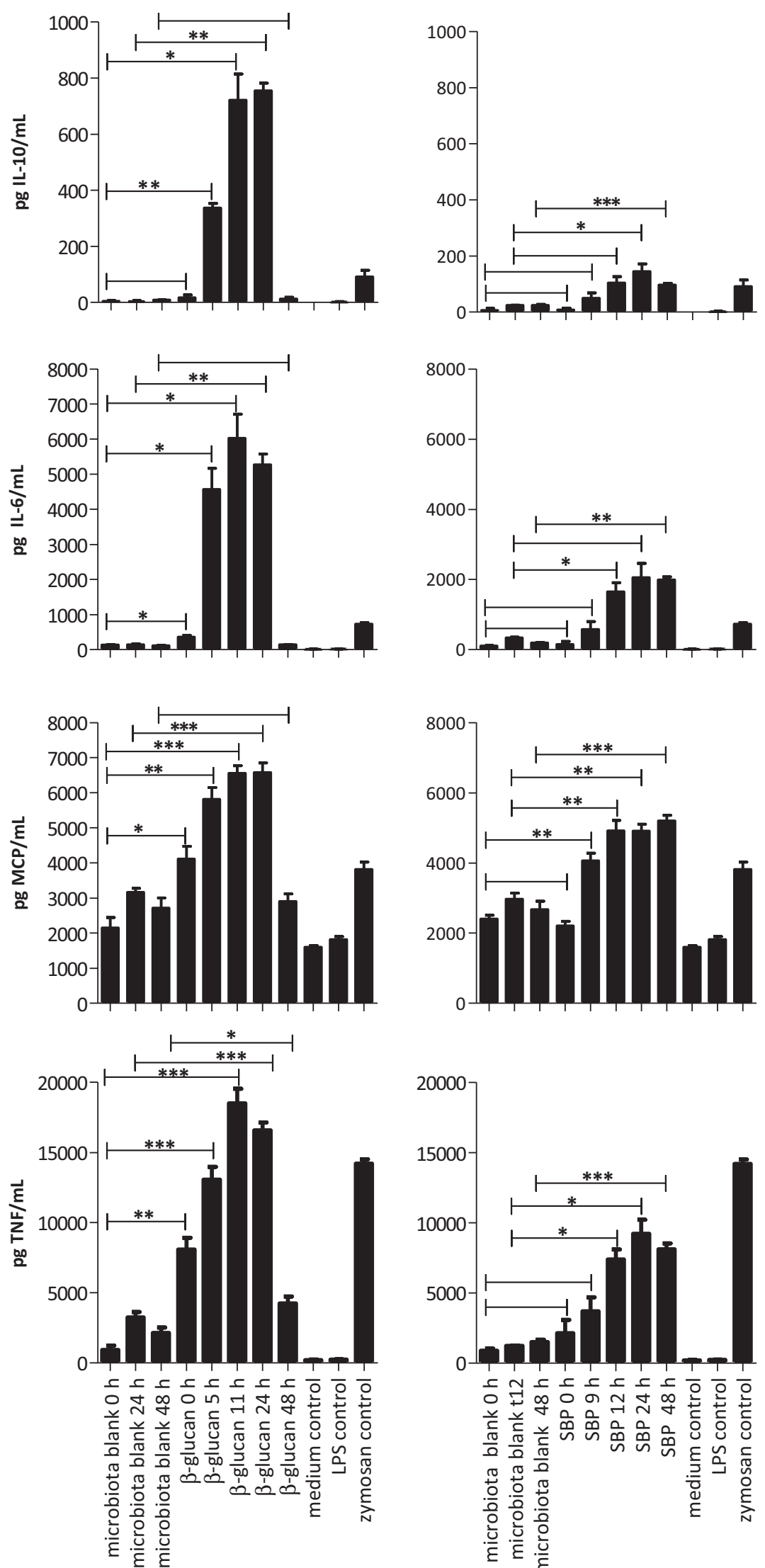
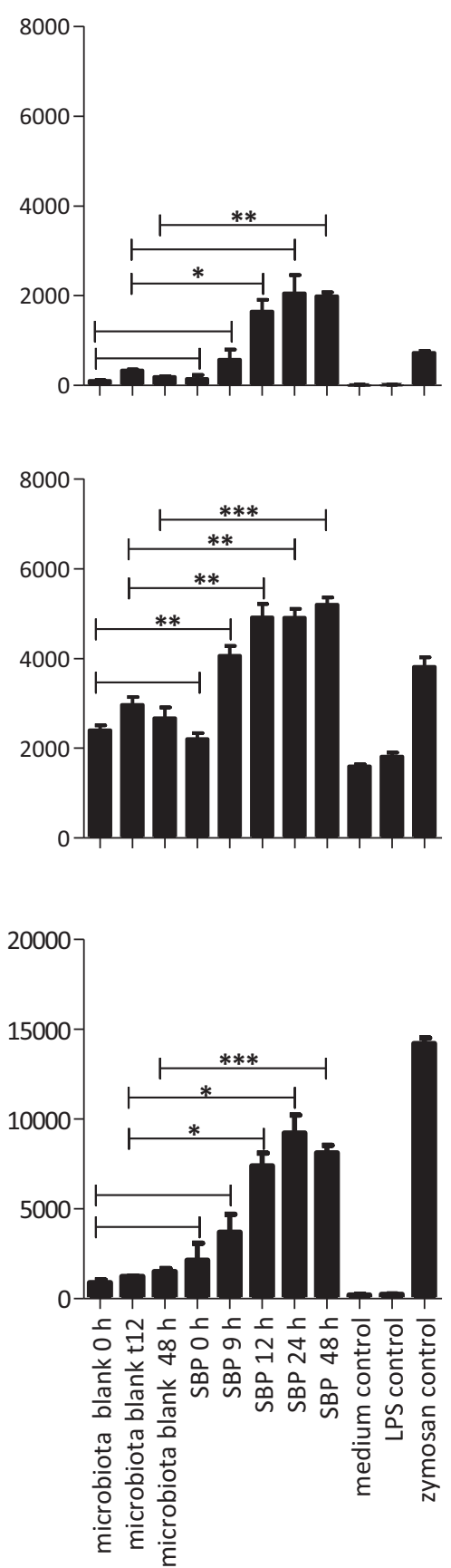

Figure 2. Induced cytokines $(\mathrm{pg} / \mathrm{mL})$ by fermentation digesta of $\beta$-glucan and SBP. Fermentation blanks contain only fermentation medium and microbiota. Stars represent classes of statistically different responses compared to the medium control $\left({ }^{*} p<0.05,{ }^{*} p<\right.$ $\left.0.01,{ }^{* * *} p<0.0001\right)$. 


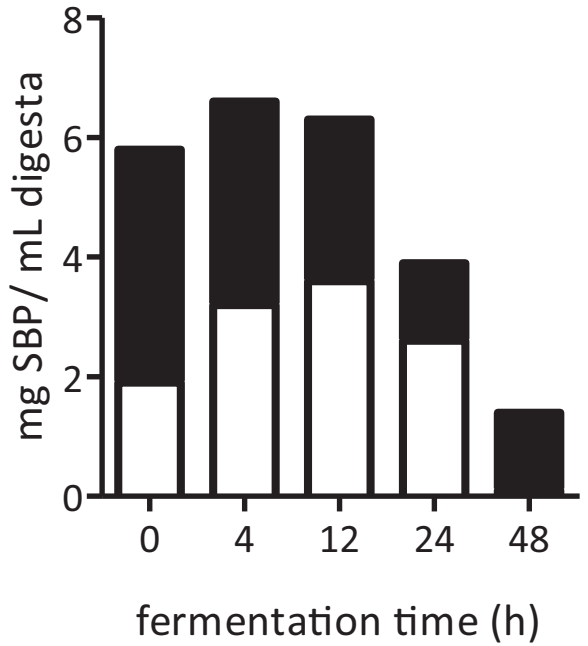

Figure 3. Amounts of soluble (black) and insoluble (white) SBP present in fermentation digesta.

\subsubsection{SBP}

For SBP the least amount of cytokines were induced at time point zero when the PS was present in its unfermented form (Fig. 2). An increase in amounts of induced cytokines was measured over time up to $24 \mathrm{~h}$. The amount of insoluble SBP increased up to $12 \mathrm{~h}$ fermentation (Fig. 3), while the total amounts of SBP remained rather constant, indicating that precipitation of the pectin occurred. With the increased amounts of insoluble SBP, also the amounts of induced cytokines increased (Fig. 2). This suggests that the strongest cytokine responses were elicited by the insoluble SBP.

From $12 \mathrm{~h}$ of fermentation onwards the total amounts of SBP decreased substantially, especially the amount of soluble SBP. Additionally, the measurements of $\mathrm{pH}$ and amounts of SCFA decreased and increased, respectively, from $12 \mathrm{~h}$ onwards, indicating that the start of the SBP fermentation began at approximately $12 \mathrm{~h}$. At $48 \mathrm{~h}$ of fermentation mainly soluble SBP was detected $(1.3 \mathrm{mg} / \mathrm{mL}$ digest) and large amounts of cytokines $(8112 \mathrm{pg} / \mathrm{mL}$ TNF) were induced by the digesta at this time point. This indicates that soluble glycosidic metabolites of SBP fermentation can also induce cytokine production in immune cells.

\subsection{PS degradation of fibers during fermentation}

As not only insoluble fibers, but also soluble fermentation metabolites seem to induce cytokines in BMDCs, the digesta were characterized for the molecular masses of the soluble PS by HPSEC (Fig. 4).

\subsubsection{Molecular mass distribution during $\beta$-glucan fermentation}

Soluble PSs were detected by HPSEC analysis (Fig. 4A). At time point $0 \mathrm{~h}$ the original molecular mass of soluble $\beta$-glucan polymer ranged between 60 and $370 \mathrm{kDa}$ and remained that size within $5 \mathrm{~h}$ of fermentation, while the amount of these molecules decreased. This was either due to its utilization by the microbiota and/or due to modification into insoluble molecules.

At $11 \mathrm{~h}$ of fermentation a shift of the higher molecular mass to ca. $60 \mathrm{kDa}$ was observed. Hence, endoacting enzymes, which degrade the glucan backbone, were present in the digest. At $11 \mathrm{~h}$ the largest amounts of cytokines were induced in the immunoassay. Within the next $13 \mathrm{~h}$ of fermentation the molecular mass of the soluble barley $\beta$-glucans remained the same. The amount of soluble $\beta$-glucans decreased, indicating that the glucans were partly degraded or precipitated. After $48 \mathrm{~h}$ the soluble polymer had almost completely disappeared.

\subsubsection{Molecular mass distribution during SBP fermentation}

The degradation profile of SBP revealed that mainly side chain degradation occurred, as no large shift of the molecular mass was observed during the fermentation, as was the case for the barley $\beta$-glucan fermentation.

Soluble PSs at time point $0 \mathrm{~h}$ consisted of a molecular mass range of $18-370 \mathrm{kDa}$. At $48 \mathrm{~h}$ of SBP fermentation, highest amounts of cytokines were induced and only soluble glycosidic fermentation metabolites were present (Fig. 3), having a molecular mass of $60 \mathrm{kDa}$ (Fig. 4B). This indicates that soluble SBP might have been responsible for the induced cytokines.

The comparison of the two fermentation substrates showed that each dietary fiber was fermented differently, which led to different metabolites and end products. This difference was expected since the substrates are different in their chemical structure and require different enzymes for degradation. Both substrates seemed to have immunomodulatory active PSs of rather similar molecular mass (60 kDa).

\subsection{OS formation during fermentation}

Since soluble PSs were detected with HPSEC, the formation of LMW and intermediate molecular mass (IMW) molecules was expected. Furthermore, soluble IMW or LMW present, could be responsible for the immunomodulation of the fermentation digesta as previously suggested [32]. The formation of LMW molecules (<DP 20; DP is degree of polymerization) and IMW molecules (>DP 20; upper DP limit cannot be predicted from the pattern) during in vitro fermentation of the two substrates was monitored by HPAEC (Fig. 5).

\subsection{1 $\beta$-Glucan fermentation degradation products}

Soluble glycan degradation products formed during the barley $\beta$-glucan degradation were detected in increasing 

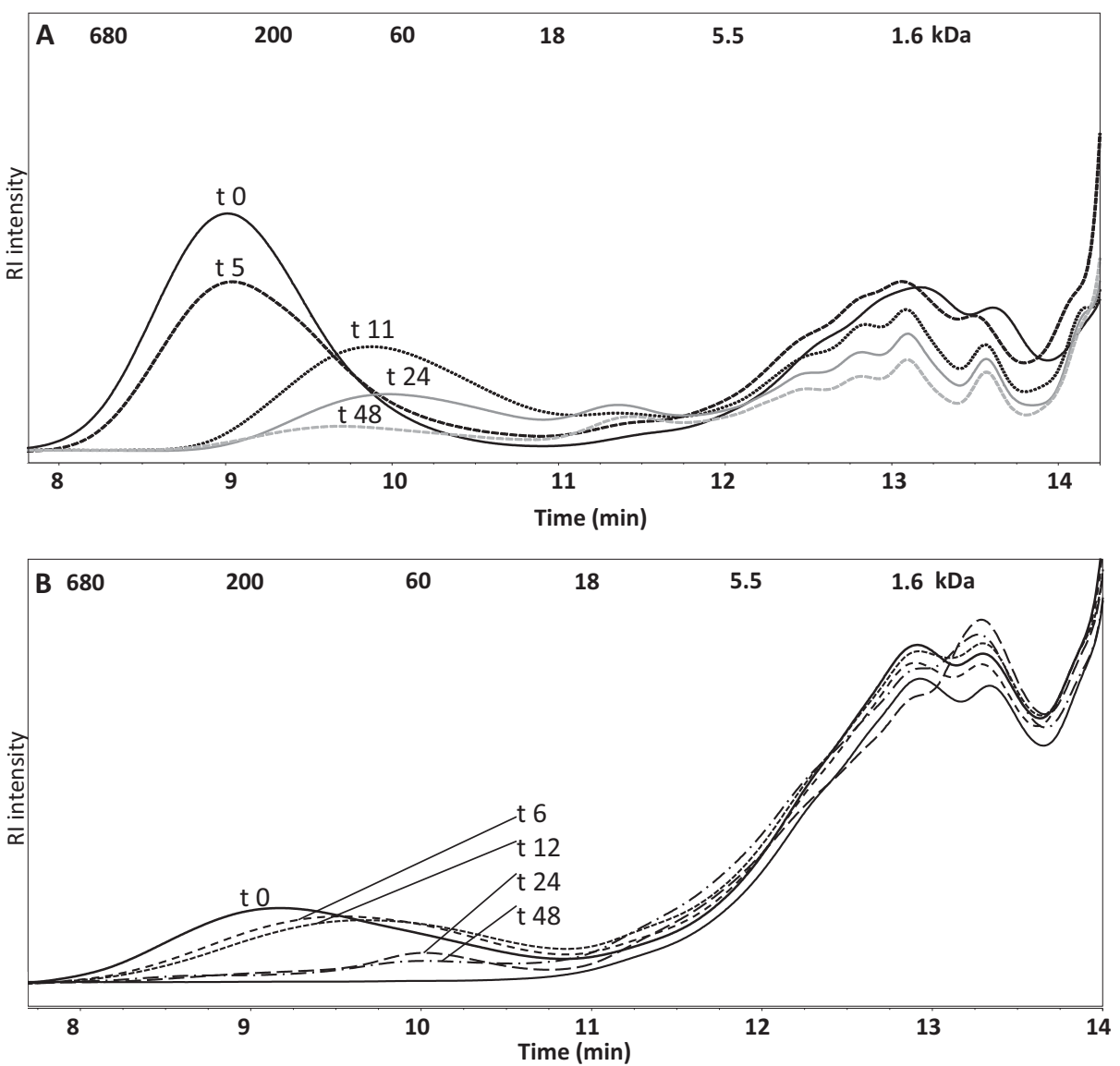

Figure 4. HPSEC PS profile of barley $\beta$-glucan $(A)(0,5,11,24,48 \mathrm{~h})$ and $\operatorname{SBP}(B)(0,6,12,24,48 \mathrm{~h})$ fermentation digesta. amounts (Fig. 5A). They were present in increasing amounts, because the fermentation of $\beta$-glucan was fast and determined by soluble and insoluble populations, leading to an imbalance in production and utilization of soluble intermediate products. The degradation products eluted mainly between retention time $\left(R_{\mathrm{t}}\right) 22$ and $50 \mathrm{~min}$, and could not be fully separated. These oligomers and disappear over fermentation time, which can be related to the fermentation of first all soluble, then followed by insoluble $\beta$-glucans at later stages of fermentation.

The fermentation digesta of 11 and $48 \mathrm{~h}$ consisted of similar soluble degradation products, but only the digesta of $11 \mathrm{~h}$ induced large amounts of cytokines. Also the $24 \mathrm{~h}$ fermentation digesta induced large amounts of cytokines, consisting of mainly soluble IMWs in comparison to the $11 \mathrm{~h}$ digesta. The only common molecules present in the 11 and $24 \mathrm{~h}$ digesta are the LMWs (eluting between $R_{\mathrm{t}} 25$ and $35 \mathrm{~min}$ ) and were in lower amounts present in the $48 \mathrm{~h}$ digesta and could thus be responsible for the immune stimulation described.

\subsubsection{SBP fermentation}

Contrary to the formation of degradation products during the $\beta$-glucan fermentation, almost no soluble OS were formed during the SBP fermentation (Fig. 5B). Only at $48 \mathrm{~h}$ of fer- mentation galacturonic acid was detected. Since the fermentation of SBP is rather slow, it could be the case that easily degradable OS metabolites were immediately utilized by the bacteria and thus not detected. The preferential fermentation of soluble fiber over insoluble fiber has been also observed for pectins present in chicory root pulp [17]. As only large soluble PS (HPSEC) were present at $48 \mathrm{~h}$ fermentation, the stimulation of cytokine secretion in BMDCs was due to large soluble PS molecules (ca. $60 \mathrm{kDa}$ ) (HPSEC) (Fig. 4).

Overall, barley $\beta$-glucan and especially SBP are rather slowly fermentable PSs under the current experimental conditions. For $\beta$-glucan this was probably due to the partial insolubility [17]. For SBP the explanation could be, besides its partly insolubility, that SBP is a rather structurally complex and difficult to degrade PSs. The potential benefit of slow fiber fermentation is that bioactive degradation products could be present in the intestine for a longer time to interact with epithelial and immune cells. In addition, fermentation is also shifted to the more distal colon parts [33].

\subsection{Fermentation profile of SBP on monosaccharide constitution level}

As it was observed that the molecular structure is also of importance for immunomodulatory activity and SBP consists of 

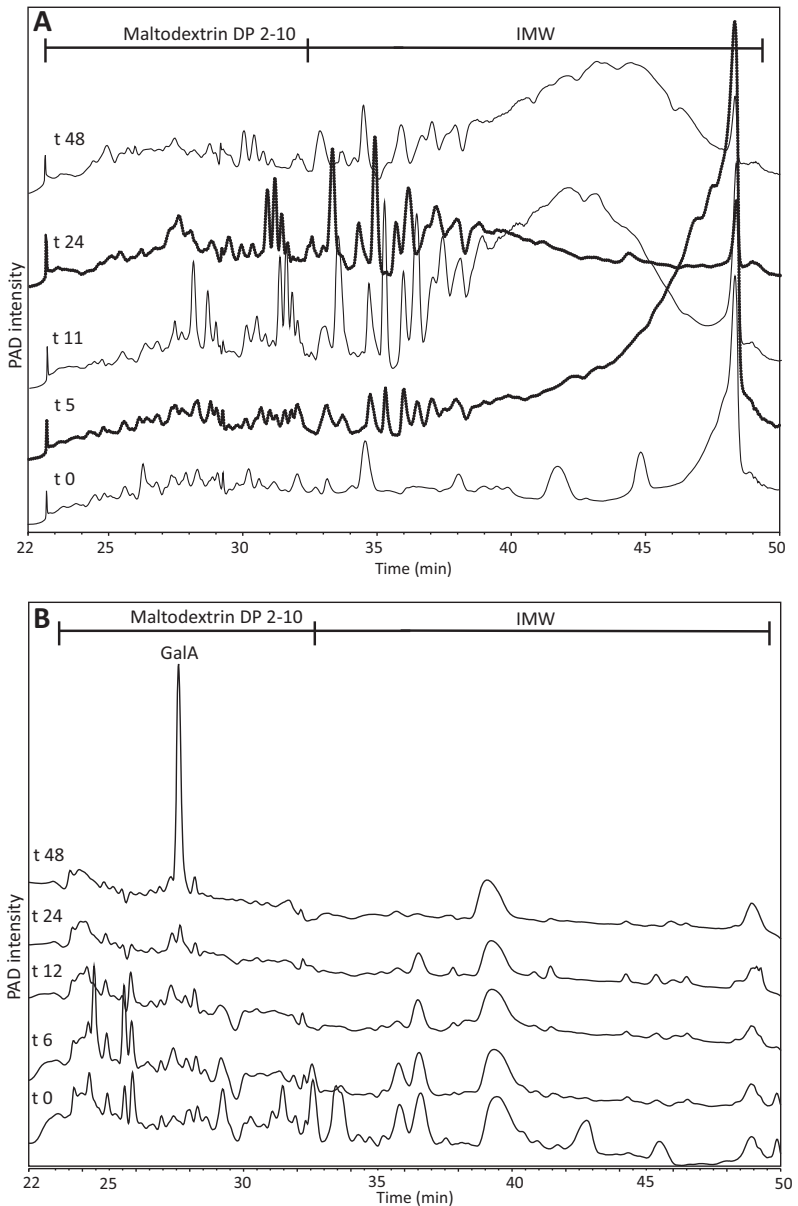

Figure 5. HPAEC elution profiles of barley $\beta$-glucan fermentation digesta (A) $(0,5,11,24,48 \mathrm{~h})$ and SBP fermentation digesta (B) $(0,6,12,24,48 \mathrm{~h})$

many different monosaccharides, it was of interest to analyze which of the glycan moieties present in the oligo- and PSs, were fermented quickly and which were still present in the digesta and not utilized by the microbiota.

Figure 6 and Supporting Information Table 3 show the utilization of soluble and insoluble arabinose, galactose, and galacturonic acid, the main monosaccharides in SBP. The amounts of soluble galacturonic acid rich fragments decreased mostly only after $12 \mathrm{~h}$ of fermentation, while soluble polymers rich in galactose and arabinose decreased continuously up to $24 \mathrm{~h}$. For the rest of the fermentation soluble galactose increased, which might originate from the degradation of the insoluble pectin fraction. Insoluble polymers rich in galacturonic acid, galactose, and arabinose increased during the first $12 \mathrm{~h}$ of fermentation and were subsequently almost completely utilized at $48 \mathrm{~h}$.

The immune-stimulating SBP digesta of $48 \mathrm{~h}$ consisted of a high amount of soluble galactose rich fragments, which suggests that soluble pectin of equal ratios of galacturonic acid and galactan could be an immune-stimulating compound.
Furthermore, the constituent monosaccharide analysis of the SBP digesta showed that no rhamnose was present in the soluble digesta. This indicates that the RG I backbone is present only in the insoluble fraction, which is confirmed by the high amounts of arabinose and galactose, which are known to be attached to the RG I backbone [12] (Supporting Information Table 3).

\subsection{Possible molecular characteristics of immune-active dietary fiber}

In the highly immunomodulating $\beta$-glucan digesta, two soluble degradation populations were present $(60 \mathrm{kDa}$ and below DP 20). An increase in immunomodulation was also observed before for enzymatically degraded barley $\beta$-glucans having lower molecular masses (unpublished data). Amounts of insoluble glycans are unknown, but assumed to be present and also to be immunomodulatory.

In the highly immunomodulating SBP digesta, soluble galactan side chains and insoluble galacturonic acid backbones were present. The total amounts of SPB and its degradation products are negatively correlated with the amounts of induced cytokines. This also indicates that SBP degradation products are more immune modulating than the parental fibers. Furthermore, for SBP a trend between increased amounts of cytokines and an increase in insoluble fibers was observed.

The induced cytokine amounts are ca. 1.6- to 5.3-fold larger for barley $\beta$-glucan than SBP digesta, depending on the type of cytokine and fermentation time point. This shows that there are differences in immunomodulatory activity between the PS and their glycan degradation products, as well as between the two different fibers. This could be related to molecular differences. In addition to the immunomodulatory effect of the parental fibers, the difference in fiber fermentation may have implications for in vivo effects upon ingestion of these fibers, and could lead to differences in health effects.

\section{Concluding remarks}

In vitro fermentation digesta can be directly incubated with BMDCS from mice lacking both TLR2 and TLR4 receptors in order to study the immunostimulatory effect of dietary fibers and their microbiota-generated degradation products. This is one of the first studies investigating the immune response to complex fermentation digesta. Glycosidic soluble and insoluble fermentation metabolites were more immunomodulating than the parental fibers. This may have implication for health effects in human individuals when ingesting different dietary fibers. This also highlights the importance and need for innovative fermentation models integrating immune cells. Furthermore, detailed fermentation studies of dietary fibers are needed, including the characterization of degradation 


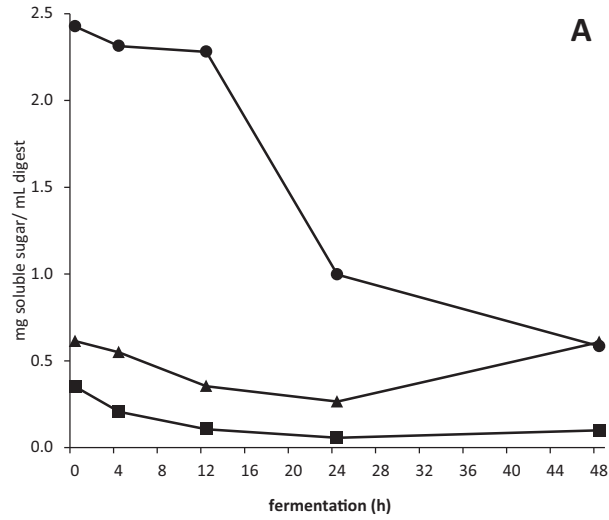

A

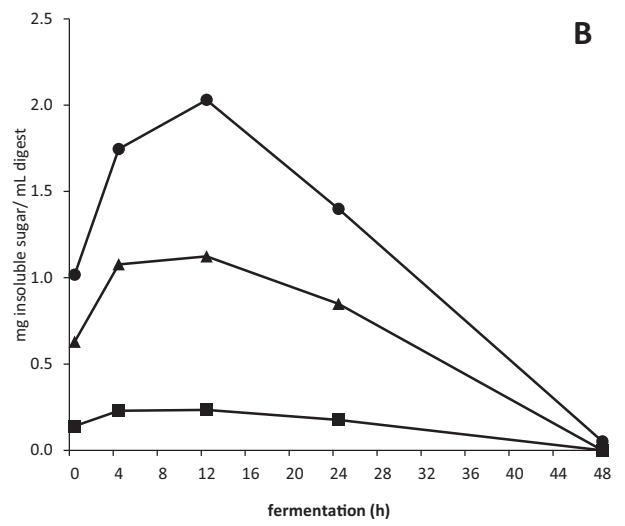

Figure 6. Amounts of soluble (A) and insoluble (B) arabinose $(\boldsymbol{\square})$, galactose $(\mathbf{\Lambda})$, and galacturonic acid (๑) present as oligoor PS in the SBP fermentation digesta. products, in order to make conclusions about beneficial health effects of dietary fibers.

All authors participated in the design of the study. C.R. prepared samples for immunoassays, performed the fermentation, characterized the substrates, performed data analysis and interpretation, and wrote the manuscript. N.T. performed the immunoassays. K.V., H.S., J.W., and H.G. contributed to data interpretation and the manuscript.

This work has been funded by TIFN (Top Institute Food and Nutrition) project GH004.2. Uttara Ramasamy is gratefully acknowledged for her help with the in vitro fermentation studies.

The authors have declared no conflicts of interest.

\section{References}

[1] European Commission, Commission Directive 2008/100/EC of 28 October 2008 amending Council Directive 90/496/EEC on nutrition labelling for foodstuffs as regards recommended daily allowances, energy conversion factors and definitions. Off. J. Eur. Union 2008, L 285, 9-12.

[2] Montagne, L., Pluske, J., Hampson, D., A review of interactions between dietary fibre and the intestinal mucosa, and their consequences on digestive health in young nonruminant animals. Anim. Feed Sci. Techol. 2003, 108, 95-117.

[3] Scott, K., Duncan, S., Flint, H., Dietary fibre and the gut microbiota. Nutr. bull. 2008, 33, 201-211.

[4] Atarashi, K., Tanoue, T., Ando, M., Kamada, N. et al., Th17 cell induction by adhesion of microbes to intestinal epithelial cells. Cell 2015, 163, 367-380.

[5] Atarashi, K., Tanoue, T., Oshima, K., Suda, W. et al., Treg induction by a rationally selected mixture of Clostridia strains from the human microbiota. Nature 2013, 500, 232 236.

[6] Ueki, T., Mizuno, M., Uesu, T., Kiso, T. et al., Expression of ICAM-I on M cells covering isolated lymphoid follicles of the human colon. Acta Med. Okayama 1995, 49, 145-151.

[7] Dambuza, I. M., Brown, G. D., C-type lectins in immunity: recent developments. Curr. Opin. Immunol. 2015, 32, 21-27.
[8] Legentil, L., Paris, F., Ballet, C., Trouvelot, S. et al., Molecular interactions of $\beta-(1 \rightarrow ; 3)$-glucans with their receptors. Molecules 2015, 20, 9745-9766.

[9] Cohen-Kedar, S., Baram, L., Elad, H., Brazowski, E. et al., Human intestinal epithelial cells respond to $\beta$-glucans via dectin-1 and Syk. Eur. J. Immunol. 2014, 44, 37293740 .

[10] Kimberg, M., Brown, G. D., Dectin-1 and its role in antifungal immunity. Med. Mycol. 2008, 46, 631-636.

[11] Remoroza, C., Cord-Landwehr, S., Leijdekkers, A. G. M., Moerschbacher, B. M. et al., Combined HILIC-ELSD/ESI-MSn enables the separation, identification and quantification of sugar beet pectin derived oligomers. Carbohydr. Polym. 2012, 90, 41-48.

[12] Schols, H. A., Coenen, G. J., Voragen, A. G. J., in: Schols, H. A., Visser, R. G. F., Voragen, A. (Eds.), Pectins and Pectinases, Wageningen Academic Publishers, Wageningen, the Netherlands 2009, pp. 19-31.

[13] Venema, K., van den Abbeele, P., Experimental models of the gut microbiome. Best Pract. Res. Clin. Gastroenterol. 2013, $27,115-126$.

[14] Marzorati, M., Vanhoecke, B., De Ryck, T., Sadaghian Sadabad, M. et al., The HMI ${ }^{\mathrm{TM}}$ module: a new tool to study the Host-Microbiota Interaction in the human gastrointestinal tract in vitro. BMC Microbiol. 2014, 14, 1-14.

[15] Possemiers, S., Pinheiro, I., Verhelst, A., Van den Abbeele, P. et al., A dried yeast fermentate selectively modulates both the luminal and mucosal gut microbiota and protects against inflammation, as studied in an integrated in vitro approach. J. Agric. Food Chem. 2013, 61, 9380-9392.

[16] Goodridge, H. S., Reyes, C. N., Becker, C. A., Katsumoto, T. R. et al., Activation of the innate immune receptor dectin-1 upon formation of a phagocytic synapse. Nature 2011, 472, 471-475.

[17] Ramasamy, U. S., Venema, K., Schols, H. A., Gruppen, H., Effect of soluble and insoluble fibers within the in vitro fermentation of chicory root pulp by human gut bacteria. $J$. Agric. Food Chem. 2014, 62, 6794-6802.

[18] Minekus, M., Smeets-Peeters, M., Bernalier, A., MarolBonnin, S. et al., A computer-controlled system to simulate conditions of the large intestine with peristaltic mixing, 
water absorption and absorption of fermentation products. Appl. Microbiol. Biotechnol. 1999, 53, 108-114.

[19] Englyst, H. N., Cummings, J. H., Simplified method for the measurement of total non-starch polysaccharides by gas liquid chromatography of constituent sugars as alditol acetates. Analyst 1984, 109, 937-942.

[20] Ahmed, A. E. R., Labavitch, J. M., A simplified method for accurate determination of cell wall uronide content. J. Food Biochem. 1978, 1, 361-365.

[21] Thibault, J., Automatisation du dosage des substances pectiques par la méthode au méta-hydroxydiphenyl. Lebensmittel-Wissenschaft und Technologie 1979, 12, 247251.

[22] Ladirat, S. E., Schuren, F. H., Schoterman, M. H., Nauta, A. et al., Impact of galacto-oligosaccharides on the gut microbiota composition and metabolic activity upon antibiotic treatment during in vitro fermentation. FEMS Microbiol. Ecol. 2014, 87, 41-51.

[23] Morgan, E., Varro, R., Sepulveda, H., Ember, J. A. et al., Cytometric bead array: a multiplexed assay platform with applications in various areas of biology. Clin. Immunol. 2004, 110, 252-266.

[24] Cone, J. W., van Gelder, A. H., Influence of protein fermentation on gas production profiles. Anim. Feed Sci. Technol. 1999, 76, 251-264.

[25] Tan, Y., Kagan, Jonathan C., A cross-disciplinary perspective on the innate immune responses to bacterial lipopolysaccharide. Mol. Cell 2014, 54, 212-223.
[26] Hayashi, F., Smith, K. D., Ozinsky, A., Hawn, T. R. et al., The innate immune response to bacterial flagellin is mediated by Toll-like receptor 5 . Nature 2001, 410, 1099-1103.

[27] Brown, G. D., Herre, J., Williams, D. L., Willment, J. A. et al., Dectin-1 mediates the biological effects of $\beta$-glucans. J. Exp. Med. 2003, 197, 1119-1124.

[28] Hooper, L. V., Epithelial cell contributions to intestinal immunity. Adv. Immunol. 2015, 126, 129-172.

[29] Johansson, M. E., Phillipson, M., Petersson, J., Velcich, A. et al., The inner of the two Muc2 mucin-dependent mucus layers in colon is devoid of bacteria. Proc. Natl. Acad. Sci. 2008, 105, 15064-15069.

[30] Loonen, L., Stolte, E., Jaklofsky, M., Meijerink, M. et al., REG3 $\gamma$-deficient mice have altered mucus distribution and increased mucosal inflammatory responses to the microbiota and enteric pathogens in the ileum. Mucosal Immunol. 2014, 7, 939-947.

[31] Abreu, M. T., Thomas, L. S., Arnold, E. T., Lukasek, K. et al., TLR signaling at the intestinal epithelial interface. J. Endotoxin Res. 2003, 9, 322-330.

[32] Sahasrabudhe, N. M., Tian, L., van den Berg, M., Bruggeman, G. et al., Endo-glucanase digestion of oat $\beta$-glucan enhances dectin-1 activation in human dendritic cells. J. Funct. Foods 2016, 21, 104-112.

[33] Jonathan, M. C., Haenen, D., da Silva, C. S., Bosch, G. et al., Influence of a diet rich in resistant starch on the degradation of non-starch polysaccharides in the large intestine of pigs. Carbohydr. Polym. 2013, 93, 232-239. 